\title{
Celebrities Acting up: A Speech Act Analysis in Tweets of Famous People
}

\author{
David Nemer \\ School of Information Science, University of Kentucky, Lexington, KY, USA \\ Email: david.nemer@uky.edu
}

Received 2 December 2015; accepted 19 December 2015; published 22 December 2015

Copyright (C) 2016 by author and Scientific Research Publishing Inc.

This work is licensed under the Creative Commons Attribution International License (CC BY). http://creativecommons.org/licenses/by/4.0/

(c) (i) Open Access

\section{Abstract}

Twitter has become very popular among celebrities. It is the main platform used by them to publish press releases and, especially, to reach out to their fans. Given the pervasiveness of celebrities on the site, people with related interests may be especially likely to start using the service due to the perception of direct access to a famous person. As for the celebrities, it is a way of being close to the public and giving them an insight in to the life of a celebrity. Although most celebrity Twitter accounts are only used for promotion purposes, many celebrities use their personal accounts for the purpose of communicating with their fans, friends and other celebrities. These celebrities tweet personal photos and share their inner thoughts for various reasons and to different audiences. Thus in this study I ask: What are celebrity speech patterns on Twitter? Are they talking mostly to fans, and if not, who are they talking to? How are they talking to these different audiences? I address these questions by analyzing the tweets publicly available on four active celebrities' Twitter timelines. The findings support that these celebrities indeed address different audiences on Twitter, including fans, friends, family and other celebrities. The findings further reveal that celebrities tend to communicate using different speech acts when talking to these different audiences. In light of this evidence, I attempt to highlight patterns that may be relevant with regards to the celebrities' gender.

\section{Keywords}

\section{Speech Act Analysis, Twitter, Celebrity, Computer Mediated Communication}

\section{Introduction}

Twitter is a web-based microblogging and social networking site (SNS) that allows registered users to communicate with short messages- "tweets"-to others. Users on Twitter follow other users or are followed. Differently from most online social networking sites, such as MySpace, Orkut or Facebook, however, the relationship of 
following and being followed requires no reciprocation: A user can follow any other user, and the user being followed does not need to follow back. Being a follower on Twitter means that the user receives all the messages (tweets) from those the user follows [1]. Common practices of responding to a tweet have evolved into a well-defined markup culture: "RT” stands for "retweet”, “@” followed by a user identifier addresses the user (at-reply), and "\#” followed by a word represents a hashtag; hashtags provide a means of grouping tweets, since one can search for the hashtag and get the set of messages that contain it [1]. This well-defined markup vocabulary combined with a strict limit of 140 characters per tweets affords users with brevity in expression. In particular, the "retweet" mechanism empowers users to spread information of their choice beyond the reach of the original tweet's followers.

Twitter has rapidly gained worldwide popularity and has recently been ranked as the second largest online social networking site on the internet ${ }^{1}$, just behind Facebook. According to the Twitter Blog [2], the platform reached over 465 million users as of 2012, generating more than 175 million tweets a day, and the microblogging site handles over 1.6 billion search queries per day. Twitter has also become very popular among celebrities. It is the main platform used by them to publish press releases and, especially, to reach out to their fans [3]. Given the pervasiveness of celebrities on the site, as Marwick and boyd [4] note, people with related interests may be especially likely to start using the service due to the "perception of direct access to a famous person" (p. 142).

As for the celebrities, it is a way of being close to the public and giving them an insight into the life of a celebrity. According to Ferris [5] "everyone" wants to know what Sir Alex Fergusson is doing at any given point of time. Fans tune into the Tom Cruise show on Twitter, catching a tiny glimpse of his life as he rushes through red carpets and exotic sets. It is a way for these celebrities to stay in touch with their fans and increase their popularity [3]. Twitter has really made this communication easier and almost effortless [6]. In the past, celebrities had to get a Web guru to create a stand-alone site and set up bulletin board systems and forums. Now celebrities have the opportunity to talk back without having to know the first thing about creating a website. Although most celebrity Twitter accounts are only used for promotion purposes, many celebrities use their personal accounts for the purpose of communicating with their fans, friends and other celebrities. These celebrities tweet personal photos and share their inner thoughts [7].

As stated in previous studies [3] [4] [8], celebrities communicate through their twitter accounts for various reasons and to different audiences. Thus in this study I ask: What are celebrity discourse patterns on Twitter? Are they talking mostly to fans, and if not, who are they addressing their tweets to? How are they talking to these different audiences? I address these questions by analyzing the tweets publicly available on four active celebrities' Twitter timelines. The findings support that these celebrities indeed address different audiences on Twitter, including fans, friends, family and other celebrities. The findings further reveal that celebrities tend to communicate using different act patterns when talking to these different audiences. In light of this evidence, I attempt to highlight patterns that may be relevant with regards to the celebrities' gender.

\section{Twitter in the Literature}

Twitter has been attracting attention from the popular press and, increasingly, from scholars [9]. Marwick and boyd [4] conducted an extensive longitudinal study to understand how celebrity is practiced through interactions among famous people and fans, friends, and other practitioners on Twitter. They collected data from the 270 most-followed celebrity Twitter accounts (as measured by Twitterholic.com during May and June 2009). They captured the tweets from these celebrities and logged the total number of tweets, average tweets, and frequency of popular Twitter practices to understand how the most-followed individuals used the site. They corresponded with some celebrities by sending "at-replies", observed more than a hundred accounts of famous people and their fans, and engaged in a deep qualitative analysis of 20 verified celebrity Twitter accounts ${ }^{2}$. Their main finding was that although celebrity practice is theoretically open to all, it is not an equalizer or democratizing discourse. Indeed, in order to successfully practice celebrity, fans must recognize the power differentials intrinsic to the relationship [4].

\footnotetext{
"Internet" is often spelled with a capital "I". But according to Markham and Baym (2009) capitalizing means that "internet" is a proper noun and implies either that it is a being or a specific place [10]. Both metaphors lead to granting the internet agency and power that are better granted to those who develop and use it.

${ }^{2}$ Twitter verifies accounts on an ongoing basis to make it easier for users to find who they are looking for. They mainly concentrate on highly sought users in music, acting, fashion, government, politics, religion, journalism, media, advertising, business, and other key interest areas They also verify business partners from time to time and individuals at high risk of impersonation (“Twitter Blog”, 2012) [2].
} 
In a more quantitative study, Honeycutt and Herring [9] analyzed how well Twitter supports user-to-user exchanges, what people are using Twitter for, and what usage or design modifications would make it (more) usable as a tool for collaboration. The study analyzes a body of naturally-occurring public Twitter messages (tweets), focusing on the functions and uses of the "@” (at-reply) sign and the coherence of exchanges [9]. The findings show an interesting degree of conversationality, facilitated especially by the use of “@” as a marker of addressivity. The study argues that although users are already using Twitter for informal collaborative purposes, it still has design limitation, such as interface issues. The authors address these limitations and propose improvements.

Because Twitter is relatively a new tool, the literature that examines the communication patterns within the microblogging site, especially celebrity-related patterns, is small, but it is moving forward and growing. Nonetheless, many gaps remain. Honeycutt and Herring [9] quantitatively analyzed overall collaboration among users, not necessarily celebrities, within Twitter, and Marwick and boyd [4] researched celebrity tweets in a very qualitative way; moreover, they did not address how celebrities talk to different audiences. The present study attempts to fill this gap as regards celebrity speech patterns on Twitter by employing speech act analysis, a mixed method approach (quantitative and qualitative).

\section{Data Sample}

In order to answer the questions "what are the celebrity speech patterns on Twitter? Are they talking mostly to fans, and if not, who are they talking to? How are they talking to these different audiences?” this study analyzes the speech acts of the publicly available tweets posted by four celebrities:

- Oprah Winfrey: talk show host, actress, producer, an American media proprietor. Winfrey is best known for her self-titled, multi-award-winning talk show, which has become the highest-rated program of its kind in history and was nationally syndicated from 1986 to 2011. She has been ranked the richest African American of the 20th century and one of the most influential women in the world [11].

- Britney Spears: an American recording artist and entertainer. Britney became an international pop culture icon immediately after launching her recording career. She is known worldwide and, as of 2011, she has sold over 100 million albums all over the world, making her one of the best-selling music artists of all time [12].

- Shaquille O'Neal: often called "Shaq", is an American former basketball player and current analyst on the television program "Inside the NBA". He played in the NBA for almost 20 years, winning this championship four times, and was elected the most valuable player (MVP) of the competition three times. He helped the American National team win the FIBA World Championship in 1994, where he was also elected the MVP of the competition [13].

- Chris Colfer: an American actor and singer, known for his portrayal of Kurt Hummel on the television series Glee. He is a Golden Globe winner for "Best Supporting Actor in a Television Series" and a two-time Emmy nominee in the "Outstanding Supporting Actor in a Comedy Series" category for his portrayal of Kurt Hummel [14].

According to Time Magazine [15], these celebrities are among the ones who use the microblogging site with the greatest frequency and interact with their followers often. Time's list does not take into consideration race, gender or type of celebrity. It is simply based on which celebrities are most active on Twitter. For this study, my choice of the celebrities was balanced for gender and race.

The celebrities' Twitter timelines were accessed once on April 20th, 2012 - 300 tweets from each timeline, for a total extraction of 1200 tweets. All tweets were collected starting from the top tweet on the celebrity's timeline until the 300th tweet. On Oprah's timeline, her tweets ranged from April 4th to April 2nd, 2012. Britney's tweets ranged from April 19th, 2012 to December 3rd, 2011. On Shaq's timeline, the selected tweets ranged from April 20th to February 13th, 2012, and Chris' tweets ranged from April 20th to March 18th, 2012.

\section{Methodology}

Data analysis was performed by applying the coding and counting approach of Computer-Mediated Discourse Analysis (CMDA) [16]. The principles of CDMA are grounded in disciplines such as linguistics, communication, and rhetoric; as such, CDMA is a good fit for computer-mediated communication analysis that is interdisciplinary in nature [17]. In order to analyze the speech acts in the tweets of celebrities, each tweet was broken down into utterances, totalizing 2283 utterances. A utterance in CDMA it is essentially a punctuation unit, similar to a sentence [18]. Utterances were counted as any sentence or sentence fragment punctuated like a complete 
sentence, unless sentence-final punctuation was not used where it should be (as in a run-on sentence) or is used improperly. Utterances such as: "hey I missed you thanks so much for your words" were counted as "hey"; "I missed you"; "thanks so much for your words".

Two categorization schemes were applied to analyze each utterance: 1) the audience that the celebrity is talking to: fans, friends, family, celebrities and general, and 2) the $16 \mathrm{CMC}$ act categories developed by Herring, Das, and Penumarthy [18] for coding speech acts in textual computer-mediated communication.

In order to come up with the audience categories, a grounded theory approach [19] was adopted: the tweets extracted from the celebrities' timeline were analyzed to identify the specific people that these celebrities were directing their tweets to. The focus of the analysis was on the message and the username (“@”; at-reply) present on the tweet. A deep qualitative exploration of the user's tweets (mentioned on the celebrity tweet) was necessary in order to identify who was the user and which category she/her would fit in most accurately. Five categories were identified, as described in Table 1.

The CMC act taxonomy is a modified and simplified adaptation of the act categories developed by Francis and Hunston [9] for spoken conversation and by Bach and Harnish [20] for formal and deliberative discourse. The CMC acts provide nuanced characterizations of interactional moves which provide a sense of how a particular type of communication was performed [17]. Table 2 summarizes how CMC acts were conceptualized by Herring, Das, and Penumarthy [18].

\section{Results}

The corpus of 2283 utterances from 1200 tweets was analyzed in order to code them for the CMC act and audience categories and answer the research questions. In Table 3, the celebrities' tweets are grouped by audience categories; the numbers of tweets are displayed both as raw numbers and as percentages of total tweets.

As shown in Table 3, Oprah and Chris mostly address their tweets to Fans, while Britney and Shaq send more tweets to a general audience. Britney communicates more often with other Celebrities as compared to Oprah, Shaq and Chris. She is the only celebrity who sent tweets to Family members. All of the celebrities sent tweets to their friends, and all had a reasonable number of tweets sent to them, with the exception of Britney Spears who only had $4 \%$ of her tweets addressing Friends.

In Table 4, the utterances are grouped by audience categories; the numbers of utterances are displayed both as raw numbers and as percentages of total utterances. The numbers in Table 4 follow the same patterns as the numbers in Table 3.

In Tables 5-8, the utterances from each celebrities' tweet are mapped to the CMC acts for a deeper and more detailed analysis. The numbers of utterances are displayed both as raw numbers and as percentages of total utterances.

According to Table 5, Oprah mostly informs her Fans (28.32\%) and accepts (28.32\%) what they say. An example is “@IAmMiniJericho yes. 23 girls just arrived in USA to look for colleges”. When it comes to communicating with Friends, she makes many claims (46.43\%) and greets them often (17.86\%), for example: “@monicas_

Table 1. Audience categories.

\begin{tabular}{|c|c|c|}
\hline Audience category & Description & Example \\
\hline Fans & $\begin{array}{l}\text { Not famous or related users on Twitter who follow } \\
\text { a celebrity and often send tweets to him or her. }\end{array}$ & $\begin{array}{l}\text { “@bythecee1 disagree. I think she has a gift } \\
\text { for helping people heal.” (By Oprah Winfrey) }\end{array}$ \\
\hline Friends & $\begin{array}{l}\text { Users on Twitter whom the celebrity knows and } \\
\text { with whom s/he has a bond of mutual affection } \\
\text { and who are not celebrities. }\end{array}$ & $\begin{array}{l}\text { “@Jennifer CAspen Honey! I’m so proud/happy } \\
\text { for you!” (By Chris Colfer) }\end{array}$ \\
\hline Family & $\begin{array}{l}\text { Users on Twitter who are blood } \\
\text { relations to the celebrity. }\end{array}$ & $\begin{array}{l}\text { “Happy 21st birthday @jamielynns pears-love } \\
\text { you and miss you! Xxoo” (by Britney Spears) }\end{array}$ \\
\hline Celebrities & $\begin{array}{c}\text { Users on Twitter who are famous, well-known, } \\
\text { command a great degree of public fascination } \\
\text { and are verified by Twitter. }\end{array}$ & $\begin{array}{l}\text { “@ParisHilton Thanks Paris for the video! } \\
\text { Your new car is so Hot! Xxoo” (by Britney Spears) }\end{array}$ \\
\hline General & $\begin{array}{l}\text { No specific user. Aimed to a general, } \\
\text { generic or universal audience. }\end{array}$ & “Happy Easter to everyone!” (by Shaquille O’Neal) \\
\hline
\end{tabular}


Table 2. CMC acts.

\begin{tabular}{|c|c|c|}
\hline CMC act & Act intention & Example $^{3}$ \\
\hline Inquire & Seek information: Inquire, make a Neutral or Marked Proposal & How long does it take? \\
\hline Request & Seek action politely: Request directly or Indirectly & Can you help me find it? \\
\hline Direct & Attempt to cause action: Require, Prohibit, Permit, Strongly advise & Cool down. \\
\hline Invite & $\begin{array}{l}\text { Seek participation/acceptance by the Addressee: } \\
\text { Solicit input, Include, Suggest, Offer (Provide goods or opportunity) }\end{array}$ & Let's go outside. \\
\hline Inform & $\begin{array}{l}\text { Provide "factual" information that is verifiable in principle, } \\
\text { even if untrue: Inform, State }\end{array}$ & The capital of India is New Delhi. \\
\hline Claim & $\begin{array}{c}\text { Make a subjective assertion that is unverifiable in principle: } \\
\text { Assert, Guess, Speculate }\end{array}$ & I love pizza! \\
\hline Desire & $\begin{array}{l}\text { A cover term including three categories of irrealis situation: } \\
\text { Desire, need (desiderative); hope, wish, dream, speculate } \\
\text { (hypothetical, counterfactual); promise (future action) }\end{array}$ & I wish I could go with you. \\
\hline Elaborate & Comment on, Explain, Paraphrase a previous utterance (usually one’s own) & I can't fake ill... mum's a teacher. \\
\hline Accept & Concur, Agree, Acquiesce & Yes, I agree. \\
\hline Reject & Disagree, Dispute, Challenge & No you can't! \\
\hline React & $\begin{array}{c}\text { Show listenership, engagement-positive, negative, or neutral: } \\
\text { Endorse, Approve }\end{array}$ & Cool!! or Eww, ick! \\
\hline Repair & Return, Clarify, Correct Misunderstanding & Did you mean “school holiday”? \\
\hline Apologize & Humble oneself, Self-deprecate & Oops my fault. \\
\hline Thank & Appreciate, Express Gratitude & Thxs for showing me/you're welcome. \\
\hline Greet & $\begin{array}{l}\text { Greeting, Leave Taking, formulaic Inquiries } \\
\text { about/wishes for others' well-being }\end{array}$ & Hi roley!!/How r u? \\
\hline Manage & $\begin{array}{l}\text { Manage discourse: Organize, prompt, focus, } \\
\text { open or close discussion, make a preamble, etc. }\end{array}$ & OK let’s get started. \\
\hline
\end{tabular}

Table 3. Tweets grouped by audience categories.

\begin{tabular}{|c|c|c|c|c|c|c|c|c|}
\hline \multirow[b]{2}{*}{ Fans } & \multicolumn{2}{|c|}{ Oprah } & \multicolumn{2}{|c|}{ Britney } & \multicolumn{2}{|c|}{ Shaq } & \multicolumn{2}{|c|}{ Chris } \\
\hline & 183 & $61 \%$ & 90 & $30 \%$ & 81 & $27 \%$ & 177 & $59 \%$ \\
\hline Friends & 48 & $16 \%$ & 12 & $4 \%$ & 69 & $23 \%$ & 63 & $21 \%$ \\
\hline Family & 0 & $0 \%$ & 3 & $1 \%$ & 0 & $0 \%$ & 0 & $0 \%$ \\
\hline Celebrity & 18 & $6 \%$ & 81 & $27 \%$ & 3 & $1 \%$ & 6 & $2 \%$ \\
\hline General & 51 & $17 \%$ & 114 & $38 \%$ & 147 & $49 \%$ & 54 & $18 \%$ \\
\hline Total & 300 & $100 \%$ & 300 & $100 \%$ & 300 & $100 \%$ & 300 & $100 \%$ \\
\hline
\end{tabular}

Table 4. Utterances grouped by audience categories.

\begin{tabular}{|c|c|c|c|c|c|c|c|c|}
\hline \multirow[b]{2}{*}{ Fans } & \multicolumn{2}{|c|}{ Oprah } & \multicolumn{2}{|c|}{ Britney } & \multicolumn{2}{|c|}{ Shaq } & \multicolumn{2}{|c|}{ Chris } \\
\hline & 339 & $62.09 \%$ & 180 & $25.53 \%$ & 90 & $20.69 \%$ & 285 & $52.20 \%$ \\
\hline Friends & 84 & $15.38 \%$ & 33 & $4.68 \%$ & 102 & $23.45 \%$ & 129 & $23.63 \%$ \\
\hline Family & 0 & $0.00 \%$ & 9 & $1.28 \%$ & 0 & $0.00 \%$ & 0 & $0.00 \%$ \\
\hline Celebrity & 30 & $5.49 \%$ & 237 & $33.62 \%$ & 9 & $2.07 \%$ & 9 & $1.65 \%$ \\
\hline General & 93 & $17.03 \%$ & 246 & $34.89 \%$ & 234 & $53.79 \%$ & 123 & $22.53 \%$ \\
\hline Total & 546 & $100 \%$ & 705 & $100 \%$ & 435 & $100 \%$ & 546 & $100 \%$ \\
\hline
\end{tabular}

${ }^{3}$ These examples were provided by Herring, Das, and Penumarthy (2005), they are not actual examples from the tweets extracted for this study. 
Table 5. Oprah’s utterances by CMC acts.

\begin{tabular}{|c|c|c|c|c|c|c|c|c|}
\hline \multicolumn{9}{|c|}{ Oprah } \\
\hline \multirow{2}{*}{$\begin{array}{c}\text { Speech act } \\
\text { Inquire }\end{array}$} & \multicolumn{2}{|c|}{ Fans } & \multicolumn{2}{|c|}{ Friends } & \multicolumn{2}{|c|}{ Celebrity } & \multicolumn{2}{|c|}{ General } \\
\hline & 24 & $7.08 \%$ & 6 & $7.14 \%$ & 0 & $0.00 \%$ & 9 & $9.68 \%$ \\
\hline Request & 9 & $2.65 \%$ & 0 & $0.00 \%$ & 0 & $0.00 \%$ & 0 & $0.00 \%$ \\
\hline Direct & 36 & $10.62 \%$ & 0 & $0.00 \%$ & 0 & $0.00 \%$ & 15 & $16.13 \%$ \\
\hline Inform & 96 & $28.32 \%$ & 12 & $14.29 \%$ & 9 & $30.00 \%$ & 39 & $41.94 \%$ \\
\hline Invite & 0 & $0.00 \%$ & 0 & $0.00 \%$ & 0 & $0.00 \%$ & 0 & $0.00 \%$ \\
\hline Claim & 81 & $23.89 \%$ & 39 & $46.43 \%$ & 15 & $50.00 \%$ & 24 & $25.81 \%$ \\
\hline Desire & 9 & $2.65 \%$ & 0 & $0.00 \%$ & 0 & $0.00 \%$ & 0 & $0.00 \%$ \\
\hline Elaborate & 12 & $3.54 \%$ & 6 & $7.14 \%$ & 0 & $0.00 \%$ & 0 & $0.00 \%$ \\
\hline Accept & 42 & $12.39 \%$ & 3 & $3.57 \%$ & 3 & $10.00 \%$ & 0 & $0.00 \%$ \\
\hline Reject & 6 & $1.77 \%$ & 0 & $0.00 \%$ & 0 & $0.00 \%$ & 0 & $0.00 \%$ \\
\hline React & 3 & $0.88 \%$ & 0 & $0.00 \%$ & 0 & $0.00 \%$ & 0 & $0.00 \%$ \\
\hline Repair & 0 & $0.00 \%$ & 0 & $0.00 \%$ & 0 & $0.00 \%$ & 0 & $0.00 \%$ \\
\hline Apologize & 3 & $0.88 \%$ & 3 & $3.57 \%$ & 0 & $0.00 \%$ & 0 & $0.00 \%$ \\
\hline Thank & 9 & $2.65 \%$ & 0 & $0.00 \%$ & 3 & $10.00 \%$ & 6 & $6.45 \%$ \\
\hline Greet & 9 & $2.65 \%$ & 15 & $17.86 \%$ & 0 & $0.00 \%$ & 0 & $0.00 \%$ \\
\hline Manage & 0 & $0.00 \%$ & 0 & $0.00 \%$ & 0 & $0.00 \%$ & 0 & $0.00 \%$ \\
\hline Total & 339 & $100 \%$ & 84 & $100 \%$ & 30 & $100 \%$ & 93 & $100 \%$ \\
\hline
\end{tabular}

twin hey girl.” Her communication with celebrities is also mostly characterized by claims (46.63\%) and informs (14.29\%); these acts are also present in the tweets posted to a general audience (inform 41.94\%; claim 25.81\%).

As shown in Table 6, Britney's tweets had "claim", "inform" and "thank" as the speech acts with the highest frequencies among all audiences. Most of the time she was sharing information with her followers about the concert she had just performed in, e.g.: "Still glowing!". This celebrity very often replied to her followers by saying caring words such as (claim): "Love u all!”, "I’m gonna miss u” and "Well you're just too sweet!”. She also replied back to her fans by thanking them for their compliments, e.g.: "@MSpearsKardash I heard!! Thank u so much... Xxoo", and to her friends and celebrity for the birthday wishes, e.g.: “@MileyCyrus Thanks Miley. Wish you all the best! Xxoo". Britney was the only one who interacted with family members, with whom she used "greet", "claim" and "direct" as the speech acts with the highest frequencies, e.g.: "Happy 21st birthday @jamielynnspears-love you and miss you! xxoo". However, since she only tweeted three times to family members, it is not possible to make a reliable analysis.

As shown in Table 7, Shaq's speech acts with the highest frequencies were "claim", "inform" and "direct" for all audiences. In his tweets, Shaq very often gave his opinions on basketball games and players (claim), e.g.: "Magic culture must change for Dwite to stay It's time for a change get him a guy like Brian shaw a guy that can push him he made me a winna”. He also informed his followers when an event was about to start and directed them to tune in, e.g.: "Diesel dunks of the weeks comn up go nbatv" and "I'm chatting with @24hourfitness on F/B this Sat @ 4pm EST 1pm PST” (inform); “Join me and my friend Lauren Fleming and her mom” and “Everybody support my girl @DeviDev’s new @MTV show \#HipHopPOV tonight at midnight!” (direct).

As shown in Table 8, Chris' speech acts with the highest frequencies were "claim" and "inform" among all audiences. Although his speech act pattern appears similar to Britney's, his tweets tend to have more substance (more elaborated and opinionated) than hers. For example, “@RedVetro I LOVE Xena! Own the whole series!” and "That awkward moment when your parents go out more than you do...”; “@nattyjb92 They're about the same actually.” and “@heyitsglee_ Still do! Three dogs and a cat!” (inform). 
Table 6. Britney’s utterances by CMC acts.

\begin{tabular}{|c|c|c|c|c|c|c|c|c|c|c|}
\hline \multicolumn{11}{|c|}{ Britney } \\
\hline \multirow{2}{*}{$\begin{array}{c}\text { Speech act } \\
\text { Inquire }\end{array}$} & \multicolumn{2}{|c|}{ Fans } & \multicolumn{2}{|c|}{ Friends } & \multicolumn{2}{|c|}{ Family } & \multicolumn{2}{|c|}{ Celebrity } & \multicolumn{2}{|c|}{ General } \\
\hline & 3 & $1.67 \%$ & 0 & $0.00 \%$ & 0 & $0.00 \%$ & 0 & $0.00 \%$ & 3 & $1.22 \%$ \\
\hline Request & 0 & $0.00 \%$ & 0 & $0.00 \%$ & 0 & $0.00 \%$ & 3 & $1.27 \%$ & 15 & $6.10 \%$ \\
\hline Direct & 6 & $3.33 \%$ & 0 & $0.00 \%$ & 3 & $33.33 \%$ & 3 & $1.27 \%$ & 12 & $4.88 \%$ \\
\hline Inform & 27 & $15.00 \%$ & 9 & $27.27 \%$ & 0 & $0.00 \%$ & 15 & $6.33 \%$ & 93 & $37.80 \%$ \\
\hline Invite & 3 & $1.67 \%$ & 0 & $0.00 \%$ & 0 & $0.00 \%$ & 0 & $0.00 \%$ & 12 & $4.88 \%$ \\
\hline Claim & 84 & $46.67 \%$ & 12 & $36.36 \%$ & 3 & $33.33 \%$ & 84 & $35.44 \%$ & 51 & $20.73 \%$ \\
\hline Desire & 12 & $6.67 \%$ & 0 & $0.00 \%$ & 0 & $0.00 \%$ & 6 & $2.53 \%$ & 6 & $2.44 \%$ \\
\hline Elaborate & 0 & $0.00 \%$ & 0 & $0.00 \%$ & 0 & $0.00 \%$ & 0 & $0.00 \%$ & 0 & $0.00 \%$ \\
\hline Accept & 3 & $1.67 \%$ & 0 & $0.00 \%$ & 0 & $0.00 \%$ & 0 & $0.00 \%$ & 0 & $0.00 \%$ \\
\hline Reject & 0 & $0.00 \%$ & 0 & $0.00 \%$ & 0 & $0.00 \%$ & 0 & $0.00 \%$ & 0 & $0.00 \%$ \\
\hline React & 15 & $8.33 \%$ & 3 & $9.09 \%$ & 0 & $0.00 \%$ & 18 & $7.59 \%$ & 18 & $7.32 \%$ \\
\hline Repair & 0 & $0.00 \%$ & 0 & $0.00 \%$ & 0 & $0.00 \%$ & 0 & $0.00 \%$ & 0 & $0.00 \%$ \\
\hline Apologize & 0 & $0.00 \%$ & 0 & $0.00 \%$ & 0 & $0.00 \%$ & 0 & $0.00 \%$ & 0 & $0.00 \%$ \\
\hline Thank & 24 & $13.33 \%$ & 3 & $9.09 \%$ & 0 & $0.00 \%$ & 60 & $25.32 \%$ & 15 & $6.10 \%$ \\
\hline Greet & 3 & $1.67 \%$ & 6 & $18.18 \%$ & 3 & $33.33 \%$ & 48 & $20.25 \%$ & 18 & $7.32 \%$ \\
\hline Manage & 0 & $0.00 \%$ & 0 & $0.00 \%$ & 0 & $0.00 \%$ & 0 & $0.00 \%$ & 3 & $1.22 \%$ \\
\hline Total & 180 & $100 \%$ & 33 & $100 \%$ & 9 & $100 \%$ & 237 & $100 \%$ & 246 & $100 \%$ \\
\hline
\end{tabular}

Table 7. Shaq's utterances by CMC acts.

\begin{tabular}{|c|c|c|c|c|c|c|c|c|}
\hline \multicolumn{9}{|c|}{ Shaq } \\
\hline \multirow{2}{*}{$\begin{array}{c}\text { Speech act } \\
\text { Inquire }\end{array}$} & \multicolumn{2}{|c|}{ Fans } & \multicolumn{2}{|c|}{ Friends } & \multicolumn{2}{|c|}{ Celebrity } & \multicolumn{2}{|c|}{ General } \\
\hline & 0 & $0.00 \%$ & 0 & $0.00 \%$ & 0 & $0.00 \%$ & 0 & $0.00 \%$ \\
\hline Request & 0 & $0.00 \%$ & 3 & $2.94 \%$ & 0 & $0.00 \%$ & 33 & $14.10 \%$ \\
\hline Direct & 15 & $16.67 \%$ & 18 & $17.65 \%$ & 0 & $0.00 \%$ & 66 & $28.21 \%$ \\
\hline Inform & 15 & $16.67 \%$ & 9 & $8.82 \%$ & 0 & $0.00 \%$ & 84 & $35.90 \%$ \\
\hline Invite & 0 & $0.00 \%$ & 0 & $0.00 \%$ & 0 & $0.00 \%$ & 0 & $0.00 \%$ \\
\hline Claim & 42 & $46.67 \%$ & 51 & $50.00 \%$ & 6 & $66.67 \%$ & 33 & $14.10 \%$ \\
\hline Desire & 0 & $0.00 \%$ & 0 & $0.00 \%$ & 0 & $0.00 \%$ & 6 & $2.56 \%$ \\
\hline Elaborate & 3 & $3.33 \%$ & 3 & $2.94 \%$ & 3 & $33.33 \%$ & 0 & $0.00 \%$ \\
\hline Accept & 9 & $10.00 \%$ & 3 & $2.94 \%$ & 0 & $0.00 \%$ & 0 & $0.00 \%$ \\
\hline Reject & 6 & $6.67 \%$ & 0 & $0.00 \%$ & 0 & $0.00 \%$ & 0 & $0.00 \%$ \\
\hline React & 0 & $0.00 \%$ & 6 & $5.88 \%$ & 0 & $0.00 \%$ & 9 & $3.85 \%$ \\
\hline Repair & 0 & $0.00 \%$ & 0 & $0.00 \%$ & 0 & $0.00 \%$ & 0 & $0.00 \%$ \\
\hline Apologize & 0 & $0.00 \%$ & 0 & $0.00 \%$ & 0 & $0.00 \%$ & 0 & $0.00 \%$ \\
\hline Thank & 0 & $0.00 \%$ & 6 & $5.88 \%$ & 0 & $0.00 \%$ & 3 & $1.28 \%$ \\
\hline Greet & 0 & $0.00 \%$ & 3 & $2.94 \%$ & 0 & $0.00 \%$ & 0 & $0.00 \%$ \\
\hline Manage & 0 & $0.00 \%$ & 0 & $0.00 \%$ & 0 & $0.00 \%$ & 0 & $0.00 \%$ \\
\hline Total & 90 & $100 \%$ & 102 & $100 \%$ & 9 & $100 \%$ & 234 & $100 \%$ \\
\hline
\end{tabular}


Table 8. Chris’ utterances by CMC acts.

\begin{tabular}{|c|c|c|c|c|c|c|c|c|}
\hline \multicolumn{9}{|c|}{ Chris } \\
\hline \multirow{2}{*}{$\begin{array}{c}\text { Speech act } \\
\text { Inquire }\end{array}$} & \multicolumn{2}{|c|}{ Fans } & \multicolumn{2}{|c|}{ Friends } & \multicolumn{2}{|c|}{ Celebrity } & \multicolumn{2}{|c|}{ General } \\
\hline & 0 & $0.00 \%$ & 0 & $0.00 \%$ & 0 & $0.00 \%$ & 0 & $0.00 \%$ \\
\hline Request & 15 & $5.26 \%$ & 6 & $4.65 \%$ & 0 & $0.00 \%$ & 3 & $2.44 \%$ \\
\hline Direct & 12 & $4.21 \%$ & 3 & $2.33 \%$ & 3 & $33.33 \%$ & 3 & $2.44 \%$ \\
\hline Inform & 87 & $30.53 \%$ & 39 & $30.23 \%$ & 0 & $0.00 \%$ & 60 & $48.78 \%$ \\
\hline Invite & 0 & $0.00 \%$ & 0 & $0.00 \%$ & 0 & $0.00 \%$ & 0 & $0.00 \%$ \\
\hline Claim & 84 & $29.47 \%$ & 51 & $39.53 \%$ & 3 & $33.33 \%$ & 36 & $29.27 \%$ \\
\hline Desire & 3 & $1.05 \%$ & 0 & $0.00 \%$ & 0 & $0.00 \%$ & 3 & $2.44 \%$ \\
\hline Elaborate & 9 & $3.16 \%$ & 6 & $4.65 \%$ & 0 & $0.00 \%$ & 6 & $4.88 \%$ \\
\hline Accept & 30 & $10.53 \%$ & 0 & $0.00 \%$ & 3 & $33.33 \%$ & 3 & $2.44 \%$ \\
\hline Reject & 24 & $8.42 \%$ & 0 & $0.00 \%$ & 0 & $0.00 \%$ & 0 & $0.00 \%$ \\
\hline React & 18 & $6.32 \%$ & 12 & $9.30 \%$ & 0 & $0.00 \%$ & 6 & $4.88 \%$ \\
\hline Repair & 0 & $0.00 \%$ & 0 & $0.00 \%$ & 0 & $0.00 \%$ & 0 & $0.00 \%$ \\
\hline Apologize & 0 & $0.00 \%$ & 0 & $0.00 \%$ & 0 & $0.00 \%$ & 3 & $2.44 \%$ \\
\hline Thank & 3 & $1.05 \%$ & 6 & $4.65 \%$ & 0 & $0.00 \%$ & 0 & $0.00 \%$ \\
\hline Greet & 0 & $0.00 \%$ & 6 & $4.65 \%$ & 0 & $0.00 \%$ & 0 & $0.00 \%$ \\
\hline Manage & 0 & $0.00 \%$ & 0 & $0.00 \%$ & 0 & $0.00 \%$ & 0 & $0.00 \%$ \\
\hline Total & 285 & $100 \%$ & 129 & $100 \%$ & 9 & $100 \%$ & 123 & $100 \%$ \\
\hline
\end{tabular}

\section{Discussion}

This study has shown that the four celebrities analyzed in this study use Twitter not only to communicate with their fans. They use the microblogging site also to address different audiences, including their friends, family, other celebrities and the general public. Although celebrities mostly talked to fans and the general public, this study shows that they sent a good amount of tweets to friends and other celebrities: Shaq, for example, had 23\% of his tweets directed to friends, and Britney had $27 \%$ of her tweets aimed at other celebrities. The results also suggest that celebrities do not use Twitter to communicate often with family members; Oprah, Shaq and Chris did not send any tweet aimed at their relatives. The only one who did so was Britney Spears, and she only sent three tweets in the period of time sampled-1\% of her tweets, which is not a sufficient amount to support any generalization.

This study reveals that celebrities tend to communicate with different speech acts when talking to different audiences. The celebrities most often inform their fans, and when it comes to communicating with their friends, they predominantly make claims. A similar pattern follows for communicating with other celebrities (mostly claims) and the general public (mostly informs). These findings suggest that celebrities will "say" more claims when they have a closer relationship to their audience.

Although claim and inform are dominant acts among the celebrities, other acts were often identified, for example, Britney had "Thank" as the third most frequent act to address her Fans, and Shaq had "direct", also, as the third most frequent act and to address his Fans.

Along with the overall patterns described above, some individual differences emerged. The communication between Oprah, Shaq, Chris and their followers seems more of substance (more elaborated and opinionated); they tweeted meaningful messages and answered questions with concrete answers. In contrast, Britney's tweets seemed to be more superficial and subjective. They consisted of words of care, such as: "Love u all!", "I'm gonna miss u" and "Well you're just too sweet!" 
Another pattern identified was that celebrities who post tweets more often (are more active) are more likely to tweet and respond to a fan. Such a pattern was observed in Oprah and Chris' behavior on the microblogging site as compared to Shaq and Britney's behavior. Although Herring [21] found that women and men often present different patterns of net participation in terms of their discourse styles, this study was not able to identify a clear contrast between the speech patterns presented by the male (Shaq and Chris) and female (Oprah and Britney) celebrities.

\section{Conclusions}

Celebrities have adopted Twitter as one of their main platforms for public relations. Although they mostly use their accounts for promotion purposes, many celebrities use their personal accounts for the purpose of communicating with their fans, and other celebrities. These celebrities tweet personal photos and share their inner thoughts for various reasons and to different audiences. Thus, in this paper I investigate the celebrities' speech patterns, their targeted audiences, and how they engage with different audiences. I addressed these questions by analyzing the tweets publicly available on four active celebrities' Twitter timelines: Oprah Winfrey, Shaquille O'Neal, Britney Spears, and Chris Colfer. The findings support that these celebrities indeed address different audiences on Twitter, including fans, friends, family and other celebrities. The findings further reveal that celebrities tend to communicate using different speech acts when talking to these different audiences.

The analysis in this study suggests that celebrities see Twitter as an online venue where they can communicate with a variety of different people. The celebrities analyzed in the present study use the microblogging site not only for professional purposes (public relations) but also to connect with family, friends, fans, other celebrities and the general public. This study also found that celebrities tend to communicate via different kinds of speech acts when directing their messages (tweets) to these different people.

As for future work, it would be interesting to extend the size of the sample presented here and include more celebrities in order to test the findings from this study and explore whether there are patterns related to celebrity gender and race since previous studies have found gender differences in celebrity websites [22] and gender and race differences in profile picture choice [23]. Also, it would be interesting to analyze the patterns of speech from the other end: fans, friends, celebrities and family's timelines. This would allow one to understand the interaction between the celebrities and these audiences and would provide more insights to why they use such speech acts. Also, in order to understand the motivations of such speech patterns, I would suggest a qualitative approach using online ethnographic methods, and actually talk to these audiences and celebrities to understand their personal inspirations.

\section{References}

[1] Kwak, H., Lee, C., Park, H. and Moon, S. (2010) What Is Twitter, a Social Network or a News Media? ACM: Proceedings of the 19th International Conference on World Wide Web, New York, 591-600. http://dl.acm.org/citation.cfm?id=1772751

[2] Twitter Blog (2012). http://blog.twitter.com/

[3] Munten, N. and Petersen, A.H. (2009) Celebrity Twitter: Strategies of Intrusion and Disclosure in the Age of Technoculture. M/C Journal, 12. http://www.journal.media-culture.org.au/index.php/mcjournal/article/viewArticle/194

[4] Marwick, A. and Boyd, D. (2011) To See and Be Seen: Celebrity Practice on Twitter. Convergence: The International Journal of Research into New Media Technologies, 17, 139-158. http://dx.doi.org/10.1177/1354856510394539

[5] Ferris, K.O. (2001) Through a Glass, Darkly: The Dynamics of Fan-Celebrity Encounters. Symbolic Interaction, 24, 25-47. http://dx.doi.org/10.1525/si.2001.24.1.25

[6] Hargittai, E. and Litt, E. (2011) The Tweet Smell of Celebrity Success: Explaining Variation in Twitter Adoption among a Diverse Group of Young Adults. New Media \& Society, 1, 170-179. http://dx.doi.org/10.1177/1461444811405805

[7] Wigley, S. and Lewis, B.K. (2012) Rules of Engagement: Practice What You Tweet. Public Relations Review, 38, 165167. http://dx.doi.org/10.1016/j.pubrev.2011.08.020

[8] Francis, G. and Hunston, S. (1992) Analyzing Everyday Conversation. In: Coulthard, M., Ed., Advances in Spoken Discourse Analysis, Routledge, London, 1-34.

[9] Honeycutt, C. and Herring, S.C. (2009) Beyond Microblogging: Conversation and Collaboration via Twitter. Proceedings of the 42th Hawai'i International Conference on System Sciences, Los Alamitos. 
[10] Markham, A. and Baym, N. (2009) Internet Inquiry: Conversations about Method. Sage, Thousand Oaks. http://dx.doi.org/10.4135/9781483329086

[11] Quintanilla, C. (2011) The Oprah Effect. CNBC. http://www.cnbc.com/id/29961298/

[12] Moodie, C. (2011) Britney Spears Pictured Backstage at Rock of Ages with Shane Ward. The Daily Mirror. http://www.mirror.co.uk/3am/celebrity-news/britney-spears-pictured-backstage-at-rock-89309

[13] NBA.com (2012). http://www.nba.com/playerfile/shaquille_oneal/bio.html

[14] Time Magazine (2012). http://www.time.com/time/specials/packages/article/0,28804,1878865_1878867_1878848,00.html

[15] Time Magazine. The 2011 Time 100 (2011). http://www.time.com/time/specials/packages/completelist/0,29569,2066367,00.html

[16] Herring, S.C. (2004) Computer-Mediated Discourse Analysis: An Approach to Researching Online Behavior. In: Barab, S.A., Kling, R. and Gray, J.H., Eds., Designing for Virtual Communities in the Service of Learning, Cambridge University Press, New York, 338-376. Preprint. http://ella.slis.indiana.edu/ herring/cmda.pdf http://dx.doi.org/10.1017/cbo9780511805080.016

[17] Das, A. (2010) Social Interaction Process Analysis of Bengalis’ on Orkut ${ }^{\circledR}$. In: Taiwo, R., Ed., Handbook of Research on Discourse Behavior and Digital Communication: Language Structures and Social Interaction, 66-87. http://dx.doi.org/10.4018/978-1-61520-773-2.ch004

[18] Herring, S.C., Das, A. and Penumarthy, S. (2005) CMC Act Taxonomy. http://www.slis.indiana.edu/faculty/herring/cmc.acts.html

[19] Glaser, B. and Strauss, A. (1967) The Discovery of Grounded Theory. Strategies for Qualitative Research. Aldine Pub. Co., New York.

[20] Bach, K. and Harnish, R. (1979) Linguistic Communication and Speech Acts.

[21] Herring, S.C. (1993) Gender and Democracy in Computer-Mediated Communication. Electronic Journal of Communication, 3. http://ella.slis.indiana.edu/ herring/ejc.doc

[22] Lambiase, J. (2003) Codes of Online Sexuality: Celebrity, Gender and Marketing on the Web. Journal of Sexuality and Culture, 7, 57-78. http://dx.doi.org/10.1007/s12119-003-1003-9

[23] Kapidzic, S. and Herring, S.C. (2011) Gender, Communication, and Self-Presentation in Teen Chatrooms Revisited: Have Patterns Changed? Journal of Computer-Mediated Communication, 17, 39-59. http://dx.doi.org/10.1111/j.1083-6101.2011.01561.x 